\title{
BCG vaccination impact on mortality and recovery rates in COVID-19: A meta-analysis
}

\author{
Surjit Singh ${ }^{1}$, Daisy Khera ${ }^{2}$, Ankita Chugh ${ }^{3}$, Sameer Khasbage ${ }^{1}$, Pushpinder S. Khera, ${ }^{4}$ Vinay Kumar Chugh ${ }^{5}$ \\ ${ }^{1}$ Department of Pharmacology; ${ }^{2}$ Department of Pediatrics; ${ }^{3}$ Department of Dentistry; ${ }^{4}$ Department of Interventional \\ and Diagnostic Radiology; ${ }^{5}$ Department of Dentistry, All India Institute of Medical Sciences, Jodhpur, India
}

\begin{abstract}
COVID-19 is a pandemic caused by SARS-CoV-2 virus which is a very worrisome public health emergency. In this study, we compared the mortality rate and recovery rate in countries with
\end{abstract}

Correspondence: Dr. Surjit Singh, Additional Professor, Department of Pharmacology, All India Institute of Medical Sciences (AIIMS), Jodhpur, Rajasthan 342005, India.

E-mail: sehmby_ss@yahoo.com

Keywords: BCG; COVID-19; SARS-CoV-2.

Ethical approval and consent to participate: Not applicable.

Availability of data and materials: The datasets used and/or analyzed during the current study are available from the corresponding author on request.

Conflict of interest: The authors declare that they have no competing interests, and all authors confirm accuracy.

Contributions: SS, DK, AC, SK, PSK, VKC, study design and planning of review, manuscript writing and editing; SS, AC, DK, literature search; SS, DK, SK, figures preparation; AC, SS, data collection and analysis; SS, DK, AC, PK, VKC, data interpretation. All the authors have read and approved the final version of the manuscript and agreed to be accountable for all aspects of the work.

Acknowledgements: We acknowledge worldometer

(https://www.worldometers.info/coronavirus/) and BCG world atlas (http://www.bcgatlas.org/), for letting us use the data for the synthesis and overall assessment.

Take Home Message: Our study shows that BCG vaccination may be protective against COVID 19, as observed by decrease mortality rates of countries with BCG vaccination policies versus countries without BGC policy.

Received for publication: 3 April 2021

Accepted for publication: 8 June 2021.

COpyright: the Author(s), 2021

Licensee PAGEPress, Italy

Monaldi Archives for Chest Disease 2021; 91:1875

doi: 10.4081/monaldi.2021.1875

This article is distributed under the terms of the Creative Commons Attribution Noncommercial License (by-nc 4.0) which permits any noncommercial use, distribution, and reproduction in any medium, provided the original author(s) and source are credited. and without BCG vaccination policy. The data of mortality of COVID-19 was extracted from worldometer (https://www.worldometers.info/coronavirus/) on $26^{\text {th }}$ July 2020 . The data of countries where BCG vaccination is being done for all individuals is taken from BCG world atlas (http://www.bcgatlas.org/index.php), updated in 2017. BCG vaccination policy recommended countries are intervention group versus countries without $\mathrm{BCG}$ vaccination policies which are regarded as control group. Pooled analysis of countries with and without BCG vaccination policy revealed mortality rate of $1.31 \%\left(95 \% \mathrm{CI}-1.31 \%\right.$ to $1.32 \%$; $\left.\mathrm{I}^{2}=100 \%, \mathrm{p}<0.01\right)$ and $3.25 \%\left(95 \% \mathrm{CI}-3.23 \%\right.$ to $3.26 \%$; $\mathrm{I}^{2}=100 \%$, p $\left.<0.01\right)$, respectively. The recovery rate in two country groups were found to be $72.60 \%(95 \% \mathrm{CI}-72.57 \%$ to $72.63 \%)$ and $55.94 \%(95 \% \mathrm{CI}-$ $55.90 \%$ to $55.98 \%$ ), respectively. 52 individuals need to be BCG vaccinated to prevent one death $(\mathrm{NNT}=52)$. In BCG vaccination program countries, there is statistically and clinically significant less mortality $(p<0.001)$ as compared to countries without BCG policy. Our findings corroborate the hypothesis that BCG vaccination may provide protection from COVID-19. High quality evidence from randomised controlled trials are required to establish causality between BCG vaccination and protection from severe COVID-19.

\section{Introduction}

SARS-CoV-2 is a zoonotically transmitted disease, with first case reported from Wuhan city of China, and has spread globally to create a pandemic [1]. The incidence and mortality in COVID19 need to be curtailed by decreasing the spread of infection and effective treatment. To curtail the spread of COVID-19 cases, the brainstorming for effective vaccines against SARS-CoV-2 is being carried out [2]. However, there are many hurdles like the inadequate response to component vaccines and chance of spread of infection with RNA and DNA vaccines.

Bacillus Calmette-Guérin (BCG) vaccination offers long term protection against tuberculosis as well as other bacterial and viral infections $[3,4]$. There is preliminary evidence of decrease in the number of cases and mortality of COVID-19 in countries with $\mathrm{BCG}$ vaccination. BCG vaccination is found to provide non-specific immunoprotection in viral infections $[5,6]$. The most probable mechanism suggested as an elucidation for protective effects of BCG is that it induces heterologous lymphocyte responses, leading to boosted immunological reactions to secondary bacterial and viral agents [7]. Heterologous lymphocyte responses modulates $\mathrm{T}$ helper 1 (TH1) and T helper 17 (TH17) responses through activation of CD4+ and CD8+ memory cells, thereby leading to enhanced secretion of various cytokines like IFN- $\gamma$ to non- 
mycobacterial infectious agents [8]. BCG-induced enhanced cytokine production in monocytes plays a role in improving clinical conditions during a secondary viral infection [9].

The World Health Organization (WHO) recommends mandatory BCG vaccination of all children and neonates of countries with high prevalence of tuberculosis [10]. Though countries have implemented different policies with regard to $\mathrm{BCG}$ vaccination depending on their incidence and prevalence of tuberculosis.

Based on the data of BCG vaccine's immunological effects and by analysing the existing epidemiological evidence, our study aims to ascertain any association between the universal BCG vaccination and COVID-19 mortality.

\section{Methods}

In this study, we compared the mortality rate and recovery rate in countries with or without BCG vaccination policy. The data of mortality of COVID-19 was obtained from worldometer (https://www.worldometers.info/coronavirus/) on $26^{\text {th }}$ July 2020. The data of countries where BCG vaccination is being done for all individuals is taken from BCG world atlas (http://www.bcgatlas.org/index.php) updated in 2017 [11]. The countries with no information about $\mathrm{BCG}$ vaccination policy or past BCG vaccination policies were included in no BCG vaccination policy countries.

Dichotomous data i.e. percentage of mortality in countries with or without BCG vaccination policy were analysed and reported along with $95 \%$ confidence interval (CI). The meta-analysis was performed as per PRISMA reporting guidelines [12]. As data from studies were not involved, no risk of bias assessment was performed [13]. In addition, no "Grading of Recommendations Assessment, Development and Evaluation (GRADE)" analysis was done [14]. GRADE recommended that analysis should not be performed for single group meta-analysis.

The meta-analysis of mortality and recovery rate was done using $\mathrm{R}$ software [15]. R software packages used were meta and metafor. Analysis was done using both random effect as well as fixed effect model. Fixed effect model is based on zero study variance assumption and difference observed in effect size among studies is due to within study variance. Random effect model takes into account the variance observed within and between the studies, hence random effect model results are more generalizable. In fixed effect model, more weight is assigned to studies with less variance and higher number of events. Therefore, the discussion is based on fixed effect model results [16]. However, conclusion should be drawn by interpreting the results of both fixed and random effect model. We performed the analysis using Freeman Tukey double arcsine transformation (DAT), which helped data to conform to normality, thereby increasing generalisability of results.

\section{Results}

\section{Mortality rates}

\section{Countries with BCG vaccination policy}

Pooled analysis of BCG vaccination policy countries revealed mortality rate of $1.31 \%\left(95 \% \mathrm{CI}-1.31 \%\right.$ to $1.32 \% ; \mathrm{I}^{2}=100 \%$, $\mathrm{p}<0.01)$, using fixed effect model. The random effect model revealed mortality rate of $0.84 \%(95 \% \mathrm{CI}-0.56 \%$ to $1.16 \%)$ (Table 1, Supplementary Figure 1). In countries with less than fifty thousand cases of COVID-19, pooled mortality rate was $0.47 \%$ (95\% CI $-0.45 \%$ to $\left.0.49 \%, \mathrm{I}^{2}=99 \%, \mathrm{p}<0.01\right)$ and $0.45 \%(95 \% \mathrm{CI}$ $-0.20 \%$ to $0.77 \%$ ), using fixed and random effect models. In countries with more than fifty thousand cases of COVID-19, pooled

Table 1. Pooled mortality rates (case fatality ratio) and pooled recovery rates of countries with BCG vaccination policies versus no BCG vaccination policy recommendations.

\begin{tabular}{|c|c|c|c|c|}
\hline \multicolumn{5}{|c|}{$\begin{array}{l}\text { Groups and outcomes } \\
\text { Mortality rates (case fatality ratio) }\end{array}$} \\
\hline Less than 50,000 cases & $\mathrm{FEM}=0.47 \% ; \mathrm{REM}=0.45 \%$ & $0.45 \%$ to $0.49 \% ; 0.20 \%$ to $0.77 \%$ & $99 \%$ & $\mathrm{p}<0.01$ \\
\hline More than 50,000 cases & $\mathrm{FEM}=2.95 \% ; \mathrm{REM}=2.73 \%$ & $2.94 \%$ to $2.96 \% ; 2.04 \%$ to $3.53 \%$ & $100 \%$ & $\mathrm{p}<0.01$ \\
\hline All countries & $\mathrm{FEM}=1.31 \% ; \mathrm{REM}=0.84 \%$ & $1.31 \%$ to $1.32 \% ; 0.56 \%$ to $1.16 \%$ & $100 \%$ & $\mathrm{p}<0.01$ \\
\hline \multicolumn{5}{|l|}{ Recovery rates } \\
\hline Less than 50,000 cases & $\mathrm{FEM}=68.85 \% ; \mathrm{REM}=70.6 \%$ & $68.76 \%$ to $68.95 \% ; 66.24 \%$ to $74.80 \%$ & $100 \%$ & $\mathrm{p}<0.01$ \\
\hline More than 50,000 cases & $\mathrm{FEM}=72.08 \% ; \mathrm{REM}=73.16 \%$ & $72.05 \%$ to $72.10 \% ; 65.72 \%$ to $80.0 \%$ & $100 \%$ & $\mathrm{p}<0.01$ \\
\hline All countries & $\mathrm{FEM}=72.60 \% ; \mathrm{REM}=71.25 \%$ & $72.57 \%$ to $72.63 \% ; 67.50 \%$ to $74.87 \%$ & $100 \%$ & $\mathrm{p}<0.01$ \\
\hline \multicolumn{5}{|c|}{ Mortality rates (case fatality ratio) } \\
\hline Less than 50,000 cases & $\mathrm{FEM}=0.62 \% ; \mathrm{REM}=1.18 \%$ & $0.57 \%$ to $0.67 \% ; 0.56 \%$ to $1.95 \%$ & $99 \%$ & $\mathrm{p}<0.01$ \\
\hline More than 50,000 cases & $\mathrm{FEM}=4.43 \% ; \mathrm{REM}=8.74 \%$ & $4.41 \%$ to $4.44 \% ; 6.26 \%$ to $11.59 \%$ & $100 \%$ & $\mathrm{p}<0.01$ \\
\hline All countries & $\mathrm{FEM}=3.25 \% ; \mathrm{REM}=2.33 \%$ & $3.23 \%$ to $3.26 \% ; 1.60 \%$ to $3.16 \%$ & $100 \%$ & $\mathrm{p}<0.01$ \\
\hline \multicolumn{5}{|l|}{ Recovery rates } \\
\hline Less than 50,000 cases & $\mathrm{FEM}=84.44 \% ; \mathrm{REM}=80.87 \%$ & $84.26 \%$ to $84.62 \% ; 73.58 \%$ to $87.30 \%$ & $100 \%$ & $\mathrm{p}<0.01$ \\
\hline More than 50,000 cases & $\mathrm{FEM}=54.84 \% ; \mathrm{REM}=72.71 \%$ & $54.79 \%$ to $54.88 \% ; 50.69 \%$ to $90.05 \%$ & $100 \%$ & $\mathrm{p}<0.01$ \\
\hline All countries & $\mathrm{FEM}=55.94 \% ; \mathrm{REM}=79.90 \%$ & $55.90 \%$ to $55.98 \% ; 73.02 \%$ to $86.04 \%$ & $100 \%$ & $\mathrm{p}<0.01$ \\
\hline
\end{tabular}

FEM, fixed effect model; REM, random effect model; p-value is for heterogeneity. 
mortality rate was $2.95 \%\left(95 \% \mathrm{CI}-2.94 \%\right.$ to $2.96 \%, \mathrm{I}^{2}=100 \%$, $\mathrm{p}<0.01)$ and $2.73 \%(95 \% \mathrm{CI}-2.04 \%$ to $3.53 \%)$, using fixed and random effect models.

\section{Countries without BCG vaccination policy}

Pooled analysis of no BCG vaccination policy countries revealed mortality rate of $3.25 \%\left(95 \% \mathrm{CI}-3.23 \%\right.$ to $3.26 \%$; $\mathrm{I}^{2}=$ $100 \%, \mathrm{p}<0.01)$, using fixed effect model. The random effect model revealed mortality rate of $2.33 \%(95 \% \mathrm{CI}-1.60 \%$ to $3.16 \%)$ (Table 1, Supplementary Figure 2). In countries with less than fifty thousand cases of COVID-19, pooled mortality rate were $0.62 \%$ $\left(95 \% \mathrm{CI}-0.57 \%\right.$ to $\left.0.67 \%, \mathrm{I}^{2}=99 \%, \mathrm{p}<0.01\right)$ and $1.18 \%(95 \% \mathrm{CI}$ $-0.56 \%$ to $1.95 \%$ ), using fixed and random effect models. In countries with more than fifty thousand cases of COVID-19, pooled mortality rate were $4.43 \%\left(95 \% \mathrm{CI}-4.41 \%\right.$ to $4.44 \%, \mathrm{I}^{2}=100 \%$, $\mathrm{p}<0.01)$ and $8.74 \%(95 \% \mathrm{CI}-6.26 \%$ to $11.59 \%)$, using fixed and random effect models.

\section{Recovery rates}

\section{Countries with BCG vaccination policy}

Pooled analysis of BCG vaccination policy countries revealed recovery rate of $72.60 \%\left(95 \% \mathrm{CI}-72.57 \%\right.$ to $72.63 \% ; \mathrm{I}^{2}=100 \%$, $\mathrm{p}<0.01)$, using fixed effect model. The random effect model revealed recovery rate of $71.25 \%(95 \% \mathrm{CI}-67.50 \%$ to $74.87 \%)$ (Table 1, Supplementary Figure 3). In countries with less than fifty thousand cases of COVID-19, pooled recovery rate were $68.85 \%$ $\left(95 \% \mathrm{CI}-68.76 \%\right.$ to $\left.68.95 \%, \mathrm{I}^{2}=100 \%, \mathrm{p}<0.01\right)$ and $70.6 \%(95 \%$ $\mathrm{CI}-66.24 \%$ to $74.80 \%$ ), using fixed and random effect models. In countries with more than fifty thousand cases of COVID-19, pooled recovery rate were $72.08 \%(95 \% \mathrm{CI}-72.05 \%$ to $72.10 \%$, $\left.\mathrm{I}^{2}=100 \%, \mathrm{p}<0.01\right)$ and $73.16 \%(95 \% \mathrm{CI}-65.72 \%$ to $80.0 \%)$, using fixed and random effect models.

\section{Countries without BCG vaccination policy}

Pooled analysis of no BCG vaccination policy countries revealed recovery rate of $55.94 \%\left(95 \% \mathrm{CI}-55.90 \%\right.$ to $55.98 \%$; $\mathrm{I}^{2}$ $=100 \%, \mathrm{p}<0.01)$, using fixed effect model. The random effect model revealed recovery rate of $79.90 \%(95 \% \mathrm{CI}-73.02 \%$ to $86.04 \%$ ) (Table 1, Supplementary Figure 4). In countries with less than fifty thousand cases of COVID-19, pooled recovery rate were $84.44 \%\left(95 \% \mathrm{CI}-84.26 \%\right.$ to $\left.84.62 \%, \mathrm{I}^{2}=100 \%, \mathrm{p}<0.01\right)$ and $80.87 \%$ (95\% CI $-73.58 \%$ to $87.30 \%$ ), using fixed and random effect models. In countries with more than fifty thousand cases of COVID-19, pooled recovery rate were $54.84 \%$ (95\% CI $-54.79 \%$ to $\left.54.88 \%, \mathrm{I}^{2}=100 \%, \mathrm{p}<0.01\right)$ and $72.71 \%(95 \% \mathrm{CI}-50.69 \%$ to $90.05 \%)$, using fixed and random effect models.

The mean mortality rates of countries with BCG programs (mean $\pm \mathrm{SD}=3.3 \pm 3.11$ ) having more than fifty thousand COVID19 cases was statistically significantly less (p-value $<0.001$ ) as compared to countries without BCG policy (mean $\pm \mathrm{SD}=9.2 \pm$ 4.47). Number needed for prevention of a case of death was calculated based on mortality rate difference between the two groups of countries. Absolute risk reduction (ARR) for prevention of death with BCG vaccination was calculated as $0.0325-0.0131=0.0194$. NNT (number needed to treat) $=1 / \mathrm{ARR}=1 / 0.0194=51.54$. Therefore, to prevent one death 52 individuals need to be BCG vaccinated.

The world map with different mortality rates represented in different colour shades is represented in Figure 1.

\section{Discussion}

In our study, the difference between the mortality rate of COVID-19 between the countries with BCG vaccination policy

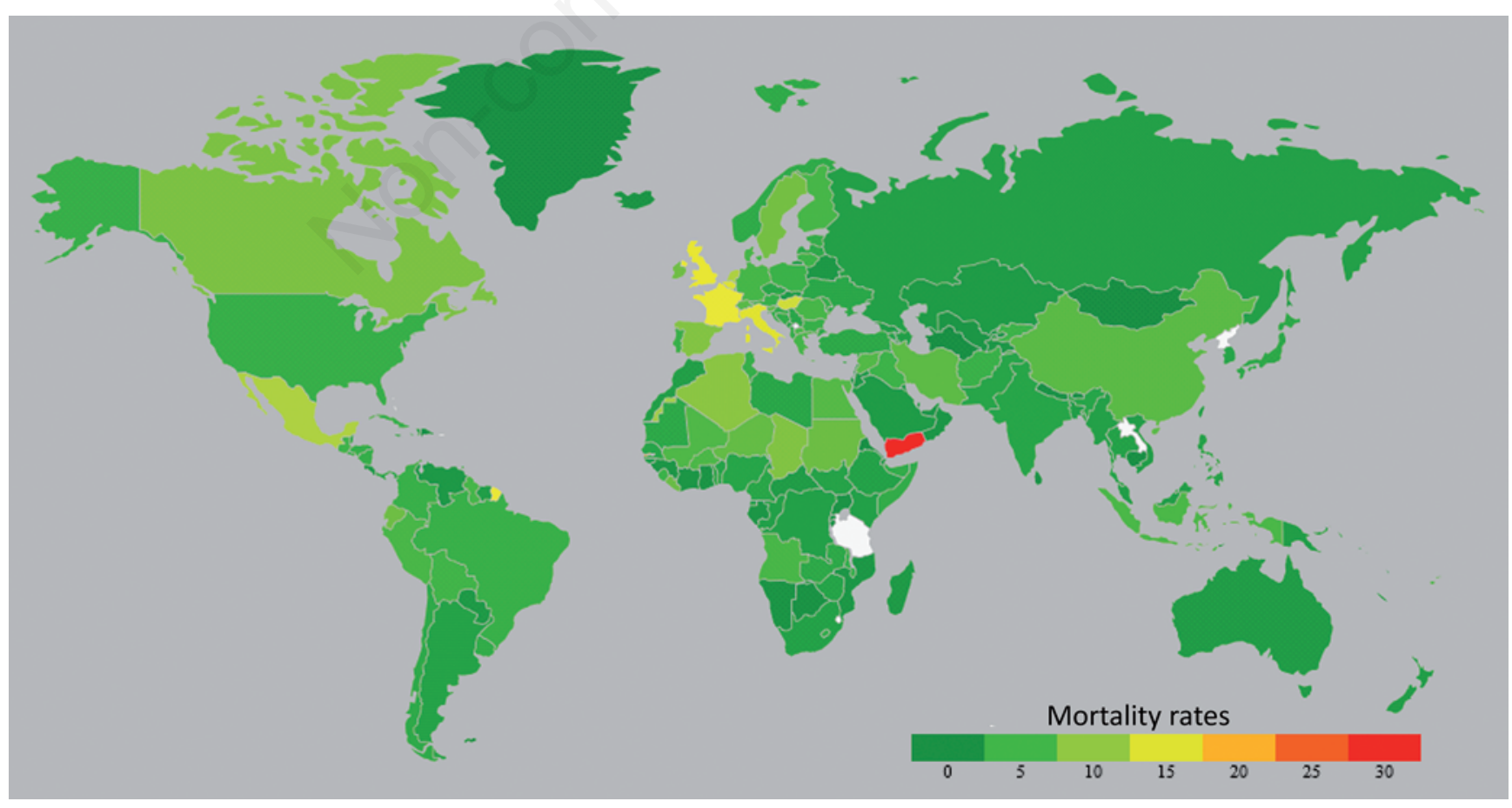

Figure 1. World map showing mortality rates in different countries worldwide. 
and those without was statistically significant. Overall, mortality rate in countries with BCG vaccination policy is around one percent and in those without is three percent.

Study done by Miller et al. and Kirov et al. excluded the countries with population less than one million because of possible confounding. Taking into account the possible confounding, we did a separate analysis of countries with less than and more than fifty thousand COVID-19 cases. In BCG vaccination policy countries with more than 50,000 COVID-19 cases, there is clinically high mortality rate of $2.95 \%$ as compared to $0.47 \%$ in countries with less than fifty thousand cases. Similarly, countries without BCG programs and with more than fifty thousand cases have reported mortality of $4.43 \%$ as compared to $0.62 \%$ mortality in countries with less than fifty thousand cases.

The increased mortality rate in countries with more than fifty thousand cases in both BCG and non BCG vaccination policy groups might be because of increased community spread. It was observed that countries in this sub-group have mortality rates ranging from $3.25 \%$ to $15 \%$. At the time of community spread, the likelihood of increased viral load during spread of infection might explain the high mortality rate in countries with more number of cases. During community spread, more individuals with comorbidities are at high risk of COVID-19 infection. The patients with more comorbid conditions were having high fatality rate due to increase cardiovascular (CVS) events. This is due to high IL-6, LDH and ferritin causing myocardial injury or may be due to direct effect of virus on cardiac functioning [17].

The difference of the recovery rate between the countries with and without BCG vaccination programs was also clinically significant. Overall, recovery rate in countries with BCG vaccination programs and no BCG vaccination programs were $72 \%$ and $56 \%$. In sub-group analysis of countries with more than 50,000 cases, the recovery rate of COVID 19 cases with no BCG vaccination implemented programs countries was far behind as compared to BCG vaccinated program implemented countries. Some of the difference could be explained by the fact that the recovery rate of some of the high burden non-BCG countries was missing.

Miller et al. [18] recently studied the correlation amid universal BCG vaccination policy and reduced COVID-19 morbidity and mortality. They included only countries (high and middle high income) with more than 1 million inhabitants. They observed that higher income countries with a current universal BCG policy (55 countries) had less number of fatality per million people. Significant higher mortality rate was observed in countries without BCG vaccination policy ( 5 countries) versus countries with established universal BCG policy.

There are few more epidemiological studies which had analysed the correlation between BCG vaccination and COVID19 infections [19-29]. Escobar et al. [30] found a strong negative correlation between degree of BCG vaccination and COVID 19 mortality in different socially comparable European countries. Escobar et al. concluded that in socially similar European countries every ten percent increase in BCG index resulted in $10.4 \%$ decreased mortality among COVID-19 patients. In addition, comparison of port of entries in US (New York, Illinois, Florida, Alabama and Louisiana - no BCG vaccination policy) versus Mexico and Brazil (BCG vaccination programs), COVID-19 mortality was significantly higher in US, despite the fact that Latin American countries have higher population density. Five studies analysed the association between BCG vaccination and COVID-19 mortality after adjusting for other confounding factors $[20,21,23,24,29]$. Sala et al. performed analysis controlling for potential confounding variables and found that BCG vaccination policy is linked to decrease in both COVID-19 cases and deaths [12]. The study done by Shet et al. showed significant negative correlation between BCG vaccination and COVID-19 incidence and mortality after adjustment for age greater than 65 years, income status and stage of pandemic [21]. The study done by Berg et al. showed significant negative correlation after controlling for age, size and population density, net migration rate, and per capita income [29]. Hensel et al. observed that countries with high testing rates $(>2,500$ test/million) did not show any correlation between BCG program and COVID-19 incidence and mortality. Testing for COVID-19 (tests per 1 million inhabitants) was one of the important confounder in their study [23]. Kirov et $a l$. and Szigeti et al. was unable to find any correlation between BCG and COVID [24,26]. Hamiel et al. [27] was unable to find any differences in COVID-19 cases with regard to two groups. However, the study was designed to report number of COVID-19 cases in a country with BCG vaccination versus no vaccination in a specific group. All individuals with $\mathrm{BCG}$ vaccination were not compared to no BCG vaccination people, as other studies.

Klinger et al. [28] did a multivariate analysis and found a strong negative correlation between mortality and BCG vaccination, similar to our study. A sub-group analysis revealed higher protection form COVID-19 to most recently vaccinated individuals. Wiwanitkit [31] suggested that since individuals vaccinated with BCG are becoming infected with COVID-19, therefore no protective role of BCG vaccination can be concluded. Wiwanitkit did not perform any analysis with regard to mortality and infectivity rate in comparison with control group [31]. Therefore such inferences are wrong and misleading. Joy et al. [32] concluded that there is protective efficacy of BCG vaccination in COVID19 infection. The analysis done by Joy et al. concluded that countries with greater than $70 \%$ BCG coverage reported around ten ( $95 \% \mathrm{CI}=-11.4$ to -8.7 ) less infection per 10,000 population versus countries with no BCG vaccination.

The proposed mechanism for protection against COVID-19 infection may involve induction of heterologous lymphocyte activation to secondary unrelated infectious agents. In addition, $\mathrm{BCG}$ vaccination can induce activation of CD4+ and CD8+ cells, modulating $\mathrm{T}$ helper 1 and $\mathrm{T}$ helper 17 cell line responses [7]. TH17 produce GM-CSF associated with induction of TH1 cells. In addition, $\mathrm{BCG}$ vaccination stimulates $\mathrm{CD} 4+$ cells to increase secretion of interferons- $\gamma$ (IFN- $\gamma$ ), thereby decreasing chances of viral infections [33]. Although the higher TH17 responses are also implicated in cytokine storm. But for prevention of viral infection, normal or higher immune response like increased TH17 and IFN- $\gamma$ are essential, as observed in many human and animal studies [5,34].

\section{Strengths and Limitations}

Different countries have different onset of the disease and we are still in the middle of the pandemic. Important confounding factors, such as rates of testing, social and economic differences, population and age structure of countries may cause bias in interpretation of results. Our study shows that BCG vaccination provides protection against severe COVID 19 and mortality associated with it. However, in the absence of well conducted randomised controlled trials, the same cannot be concluded. 


\section{Conclusions}

- Our study showed that BCG vaccination confers protection against severe COVID-19 and mortality associated with it.

- There is low quality evidence that BCG vaccination provides protection against COVID-19.

- Since we are still in the middle of the COVID-19 pandemic, it may be erroneous to come to conclusions.

- High quality evidence should be generated from randomized controlled trials before considering a global change in BCG vaccination policy and confirming to conclusion that $\mathrm{BCG}$ confers protection against COVID 19 mortality.

\section{References}

1. Yoo HS, Yoo D. COVID-19 and veterinarians for one health, zoonotic- and reverse-zoonotic transmissions. J Vet Sci 2020;21:e51.

2. Henderson DK, Haessler S, Hayden MK, et al. Whither immunity? The search for effective, durable immunity to COVID19. Infect Control Hospl Epidemiol 2020:1-8.

3. Higgins JP, Soares-Weiser K, Lopez-Lopez JA, et al. Association of BCG, DTP, and measles containing vaccines with childhood mortality: systematic review. BMJ 2016;355:i5170.

4. Aronson NE, Santosham M, Comstock GW, et al. Long-term efficacy of BCG vaccine in American Indians and Alaska Natives: A 60-year follow-up study. JAMA 2004;291:2086-91.

5. Moorlag S, Arts RJW, van Crevel R, Netea MG. Non-specific effects of BCG vaccine on viral infections. Clin Microbiol Infect 2019;25:1473-8.

6. Abbas AM, AbouBakr A, Bahaa N, et al. The effect of BCG vaccine in the era of COVID-19 pandemic. Scand J Immunol 2020; 22:e12947.

7. Goodridge HS, Ahmed SS, Curtis N, et al. Harnessing the beneficial heterologous effects of vaccination. Nat Rev Immunol 2016;16:392-400.

8. Kleinnijenhuis J, Quintin J, Preijers F, et al. Long-lasting effects of BCG vaccination on both heterologous Th1/Th17 responses and innate trained immunity. $\mathrm{J}$ Innate Immun 2014;6:152-8.

9. Kleinnijenhuis J, Quintin J, Preijers F, et al. Bacille CalmetteGuerin induces NOD2-dependent nonspecific protection from reinfection via epigenetic reprogramming of monocytes. Proc Natl Acad Sci USA 2012;109:17537-42.

10. World Health Organization. Global Tuberculosis Control: Surveillance, Planning, Financing. Accessed: 12 August 2020. Available from: https://apps.who.int/iris/bitstream/ handle/10665/42889/9241562641.pdf;jsessionid=404A8A571E459 B8F088B5913421A3E5B?sequence=2

11. Zwerling A, Behr MA, Verma A, et al. The BCG World Atlas: a database of global BCG vaccination policies and practices. PLoS Med 2011;8:e1001012.

12. Moher D, Liberati A, Tetzlaff J, et al. Preferred reporting items for systematic reviews and meta-analyses: the PRISMA statement. BMJ 2009;339:b2535.

13. Sterne JAC, Savovic J, Page MJ, et al. RoB 2: a revised tool for assessing risk of bias in randomised trials. BMJ 2019; 366:14898.

14. GRADEpro GDT [Internet]. GRADEpro Guideline Development Tool [Software]. McMaster University, 2015 (developed by Evidence Prime, Inc.). Available from: gradepro.org

15. R Core Team. R: A language and environment for statistical computing. Vienna: R Foundation for Statistical Computing; 2017. Available from: https://www.R-project.org/.

16. Higgins J, Green S. Cochrane Handbook for Systematic Reviews of Interventions: The Cochrane Collaboration; 2011. Accessed: 202028 May. Available from: www.handbook. cochrane.org.

17. Clerkin KJ, Fried JA, Raikhelkar J, et al. COVID-19 and cardiovascular disease. Circulation 2020;141:1648-55.

18. Miller A, Reandelar M, Fasciglione K, et al. Correlation between universal BCG vaccination policy and reduced morbidity and mortality for COVID-19: an epidemiological study. medRxiv 2020;20042937

19. Hegarty P, Kamat A, Zafirakis H, Dinardo A. BCG vaccination may be protective against Covid-19. ResearchGate 2020.

20. Sala G, Miyakawa T. Association of BCG vaccination policy with prevalence and mortality of COVID-19. medRxiv 2020;20048165.

21. Shet A, Ray D, Malavige N, et al. Differential COVID-19-attributable mortality and BCG vaccine use in countries. [preprint]. medRxiv. DOI: 10.1101/2020.04.01.20049478 2020.

22. Goswami R, Mittal D, Goswami R. Interaction between malaria transmission and BCG vaccination with COVID-19 incidence in the world map: A cross-sectional study. medRxiv 2020;20052563.

23. Hensel J, McGrail D, McAndrews K, et al. Exercising caution in correlating COVID-19 incidence and mortality rates with BCG vaccination policies due to variable rates of SARS CoV2 testing. medRxiv 2020;20056051.

24. Kirov S. Association between BCG policy is significantly confounded by age and is unlikely to alter infection or mortality rates. medRxiv 2020;20055616.

25. Dayal D, Gupta S. Connecting BCG Vaccination and COVID19: Additional Data. medRxiv 2020;20053272.

26. Szigeti R, Kellermayer D, Kellermayer R. BCG protects against COVID-19? A word of caution. medRxiv 2020; 20056903.

27. Hamiel U, Kozer E, Youngster I. SARS-CoV-2 rates in BCGvaccinated and unvaccinated young adults. JAMA 2020; 323:2340-1.

28. Klinger D, Blass I, Rappoport N, Linial M. Significantly improved COVID-19 outcomes in countries with higher BCG vaccination coverage: A multivariable analysis. Vaccines (Basel) 2020;8:378..

29. Berg MK, Yu Q, Salvador CE, et al. Mandated Bacillus Calmette-Guerin (BCG) vaccination predicts flattened curves for the spread of COVID-19. Sci Adv 2020;6:eabc1463.

30. Escobar LE, Molina-Cruz A, Barillas-Mury C. BCG vaccine protection from severe coronavirus disease 2019 (COVID-19). Proc Natl Acad Sci USA 2020;117:17720-6.

31. Wiwanitkit V. COVID-19 death and BCG vaccination. Tuberc Respir Dis (Seoul) 2021;84:84.

32. Joy M, Malavika B, Asirvatham ES, et al. Is BCG associated with reduced incidence of COVID-19? A meta-regression of global data from 160 countries. Clin Epidemiol Glob Health 2021;9:202-3.

33. Mathurin KS, Martens GW, Kornfeld H, Welsh RM. CD4 Tcell-mediated heterologous immunity between mycobacteria and poxviruses. J Virol 2009;83:3528-39.

34. O'Neill LAJ, Netea MG. BCG-induced trained immunity: can it offer protection against COVID-19? Nat Rev Immunol 2020;20:335-7. 